\title{
Jill Barr and Lesley Dowding: Leadership in Health Care
}

\author{
Wolfgang Böcking
}

Published online: 6 January 2009

(C) Springer-Verlag 2008

Barr and Dowding treat the subject of leadership in health care in three main parts: the individual, the team and the organisation. In part one, they provide an overview of the different styles of leadership including tests and methods to appreciate yourself and other people in order to develop your own style of leadership. For example, they refer to the principles of the SWOT analysis or the Meyers-Briggs Type Indicator.

In the second part, they compile the dynamics of a team and key points for good communication. The different types of conflicts - intrapersonal, interpersonal and intergroupare described. This consciousness is aimed at enabling development of the appropriate strategy to solve conflicts. For managing conflicts and identifying when conflicts evolve, NLP is displayed as a helpful method.

The third part gives a short introduction to types of organisational structures, different kinds of change in organisations and different quality models like TQM or EFQM. They describe theories of change, how to respond to change and lead a team through change. The topics are mostly explained in reference to the British NHS. The summary ends with a short outlook towards the need of adopting the different styles of leadership to a broad variety of health care settings.

Each chapter begins with a short description of what to expect to learn and ends with a short summary. Within the short examples, situations within the context of health care are used. However, the specific problems between the different staff groups like doctors, nurses, employees in the administration and patients and the conflicts which resulting from the different fields of action are discussed only marginally.

Leadership in Health Care gives students or young professionals a first impression of leadership in general. For more experienced readers, who are already working in the health care business, it provides only limited added depth. Overall, the book illustrates the main topics of leadership and the most common methods. However, the transfer to specific problems of leadership in health care is only partly achieved.

W. Böcking $(\bowtie)$

Technical University Dresden,

Fiedlerstr. 27,

01307 Dresden, Germany

e-mail: wolfgang.boecking@web.de 